\title{
PENGARUH MOTIVASI DAN DISIPLIN KERJA TERHADAP KINERJA KARYAWAN SPBUCOCO PLAJU 21.302.04 PALEMBANG
}

\author{
Riri Hanifa, Dewi Purnama Sari \\ Universitas Sumatera Selatan \\ ririhanifa@uss.ac.id
}

\begin{abstract}
ABSTRAK
Tujuan

penelitianiniadalahuntukmengetahuibagaimanapengaruhmotivasi dan disiplinkerjaterhadapkinerjakaryawanSPBUCocoPlaju 21.302 .04 palembang.Penelitian inimenggunakanmetodedeskriptif. Pengambilan data pada penelitianinimenggunakankuesioner. Sampel dalampenelitianiniberjumlah 35 responden yang merupakankeseluruhankaryawanSPBUCocoPlaju 21.302.04 Palembang. Metode analisis data yang digunakandalampenelitianiniadalahanalisisregresiberganda.Hipotesis pada penelitianinidibuktikandenganpengujianhipotesis, dimana fhitungsebesar1825,684lebihbesardari ftabeldengantingkatsignifikansi 0,000 lebihkecildaritingkatprobilitas alpha 0,05, sehinggasecarasimultanvariabelmotivasi dan disiplinkerjaberpengaruhsignifikanterhadapkinerjakaryawanSPBUCocoPl aju 21.302.04 Palembang. Selain itumberdasarkannilai thitunguntukvariabelmotivasi dan disiplinkerja masing-masing sebesar 0,074 dan 0,061yang lebihbesardari ttabeldan lebihkecildariprobabilitas alpha 0,05, sehinggasecaraparsialvariabelmotivasi dan disiplinkerjaberpengaruhsignifikanterhadapkinerjakaryawanSPBUCocoPl aju 21.302.04 Palembang. Maka sebagaitindaklanjutatau saran, pimpinanSPBUCocoPlaju 21.302.04 Palembangharustetapmemperhatikan dan menjagakeduafaktortersebuttetapberadadalamkondisiyang baik dan jikamungkindapatditingkatkanlagi.
\end{abstract}

Kata kunci: Motivasi, Disiplin dan Kinerja Karyawan

\begin{abstract}
The purpose of this study was to determine how the influence of motivation and work discipline on the performance of employees at the CocoPlaju gas station 21.302.04 Palembang.This research uses a descriptive method. Collecting data in this study using a questionnaire. The sample in this study amounted to 35 respondents who were all employees of the CocoPlaju gas station 21.302.04 Palembang. The data analysis method used in this research is multiple regression analysis. The hypothesis in this study is proven by an $f$ test, where $f$ count is 1825,684 which is greater than $f$ table with a significance level of 0.000 less than the probability level of 0.05 alpha, so that simultaneously the motivation and work discipline variables have a significant effect on the performance of the Coco gas station employees. Plaju 21302.04 Palembang. In addition, based on the calculated $t$ value for the motivation and work discipline variables, respectively 0.074 and 0.061 , which is greater than the t table and smaller than the alpha probability of 0.05 , so that partially the
\end{abstract}


motivation and work discipline variables have a significant effect on the performance of the Coco gas station employees. Plaju 21302.04 Palembang. So as a follow-up or suggestion, the head of the CocoPlaju gas station 21,302.04 Palembang must continue to pay attention and keep these two factors in good condition and if possible, it can be improved better.

Keywords: Motivation, Discipline and Employee Performance

\section{LATAR BELAKANG}

Keberhasilansuatuperusahaan

sangat dipengaruhi

oleh kinerjaindividukaryawannya.

Setiapperusahaanakanselaluberusahauntukmendapatkankinerjaterbaikdarikaryawannya, denganharapanapa yang menjaditujuanperusahaanakantercapai. Mangkunegara (2017) berpendapatbahwakinerjaadalahhasilkerjasecarakualitasdankuantitas yang dicapai oleh seseorangpegawaidalamkemampuanmenjalankantugas-

tugassesuaidengantanggungjawabyangdiberikanolehatasankepadanya.

$\begin{array}{lll}\text { Menurutkasmir (2016) } & \text { kinerjamerupakanhasilkerja dan }\end{array}$ perilakukerjayangtelahdicapaidalammenyelesaikantugas-tugas dan tanggungjawab yang diberikandalamsuatuperiodetertentu.

Apabilakinerjadaritanggungjawabitutelahtercapaisesuaitujuanperusahaanmakaperusahaan akanmengalami

peningkatan. Kinerja karyawandalamsuatuorganisasidapatdipengaruhi oleh berbagaifaktoryaitumotivasi dan disiplinpegawai. Dimana motivasidapatmempengaruhiperilaku-perilakupegawaidalamsuatuorganisasi.

MenurutBangun (2012) Motivasi, berasaldari kata, motif (motive), yang berartidorongan. Dengandemikianmotivasiberartisuatukondisi yang mendorongataumenjadisebabseseorangmelakukansuatuperbuatanataukegiatan, yang berlangsungsecarasadar. Pemberianmotivasi sangat pentingdalamsetiapperusahaan. Karyawan yang mempunyaimotivasikerja yang tinggiakandapatmendorongkaryawantersebutbekerjalebihsemangatsertadapatmemberikan kontribusipositifterhadappekerjaan yang telahmenjaditanggungjawabnya. Tanpamotivasi, seorangkaryawantidakdapatmemenuhipekerjaannyasesuaistandarataumelampuistandarkar enaapa yang menjadimotivasidalambekerjatidakterpenuhi. Sekalipunseorangkaryawan yang

memilikikemampuandalambekerjatinggitetapitidakmemilikimotivasiuntukmenyelesaikant ugasnyamakahasilakhirdalampekerjaannyatidakakanmemuaskan.

$$
\text { MenurutRivai (2013) Untukmenciptakankinerjakaryawan agar }
$$

berjalandenganefektif,

haltersebuttidakhanyadidorongdenganadanyamotivasisajatetapidenganmempunyaidisiplin kerja yang tinggi. Disiplinadalahprosedur yang mengoreksiataumenghukumbawahankarenamelanggarperaturanatauprosedur.

Disiplinkerjaadalahsuatualat yang digunakan para manajeruntukberkomunikasidengankaryawan agar merekabersediauntukmengubahsuatuperilakusertasebagaisuatuupayauntukmeningkatkank esadaran juga kesediaanseseorang agar mentaatisemuaperaturan dan normasosial yang berlaku di suatuperusahaan. Tanpaadanyadisiplin, makasegalakegiatan yang akandilakukanakanmendatangkanhasil yang kurangmemuaskan dan tidaksesuaidenganharapan. Jika dilihatsecara rill, faktorkedisiplinanmemegangperanan yang amatpentingdalampelaksanaantugassehari-harikaryawan.

Terry dan Sutrisno (2017) disiplinmerupakanalatpenggerakkaryawan. Agar tiappekerjaandapatberjalandenganlancar,makaharusdiusahakan agar adadisiplin yang baik. Terry kurangsetujujikadisiplinhanyadihubungkandenganhal-hal yang 
kurangmenyenangkan (hukuman), karenasebenarnyahukumanmerupakanalat paling akhiruntukmenegakkankedisipliankaryawanataupegawai.

Manfaat

daridisiplinitusendiribanyaksekalisepertimenumbuhkan rasa kepedulian,

mengajarkanketeraturan

menjadipolahidupteratur,dapatmengontrolemosisehinggabekerjatidaktergesa-

gesa,danmenumbuhkankepatuhanuntukmematuhiaturan-aturan yang ada.

ObjekpenelitianiniadalahSPBUCocoPlaju 21.302.04

yang SPBUCocoPlaju 21.302.04 Palembang adalahsebuahperusahaanyang bergerak di bidangpemasaranproduk dan pelayanankepadakonsumen yang telahberjalanselamakuranglebih 11 tahun yangberalamat diJalan JendralAhmad Yani No. 58-24, 14 ulu, Kecamatan Seberang Ulu II, kota Palembang. SPBUinimerupakananakperusahaandariPT.PertaminaSPBUCocoPlajuinimemasarkanBB Mpertalite,pertamax 92,pertamax turbo,pertaminadexdan dexlite.KeberhasilanSPBUCocoPlaju21.302.04 Palembang tergantung pada kinerjakaryawannya. Jika kinerjakaryawanbaiktentunya target perusahaanakandapattercapai

Berdasarkanhasilobservasiawal, jumlahkaryawan di SPBUCocoPlaju 21.302.04 Palembang adalahsebanyak35 orang dengantingkatanprofesi yang berbeeda-beda, sedangkangajiatauupahpertahunselalumeningkat yang sesuaidenganstandarUMK Palembang untuktetapbisamemenuhikebutuhan primer maupunkebutuhansekunderkaryawan.Untuksistempengawasan di lapangan di lakukan oleh kepala shift untukmenggantikan operator makansiang dan sholat. Kondisilingkungan di area luarSPBUterlihatbersih dan terawatt begitupunsebaliknya di dalamruangan. HubunganantarkaryawanSPBUterjalinbaik dan salingmembantu. Permasalahan yang terjadi di SPBUmenurunnyakinerjakaryawandalammenyelesaikanpekerjaan. Hal inidapatterlihatdariseringnya operator terlambatdatangsaatakanmelakukanoper sift dan seringnya operator tidakmasukbekerjadenganberbagaialasan.

Permasalahan

tata

tertibdianggapkurangtegasdalamimplementasinyaterhadapkaryawan yang telat. Keterlambatankaryawantidakmendapatperhatiankhususdariatasan. Permasalahan yang munculdalamaspekkinerjasangatmungkindipengaruhifaktormotivasikarenaberdasarkanhas ilobservasiawal di lapangan, para karyawanterlihatkurangbersemangatsaatbekerja. Selain motivasi, faktordisiplinkerja juga mungkinmenjadipenyebabpermasalahandalamaspekkinerjakaryawan.

Dari hasilpenelitianterdahuluvariabelmotivasi

dan disiplinkerjaberpengaruhterhadapkinerjakaryawan, variabelmotivasi yang diteliti oleh Rikhayati (2018) menunjukkanadanyapengaruhpositifterhadapkinerjakaryawan. Sedangkanvariabeldisiplinpengaruhpositifterhadapkinerjakaryawan. Darmastuti (2014) menunjukkanvariabelmotivasiberpengaruhpositifterhadapvariabelkinerjakaryawansedang kanvariabeldisiplinmenunjukkanpengaruhnegatifterhadapvariabelkinerjakaryawan.

Rizonpranata (2014) menunjukkanvariabelmotivasi dan disiplinkerjaberpengaruhnegatifterhadapkinerjakaryawan.

Berdasarkanuraian di

makapenelitianinimencobamenganalisispengaruhvariabelmotivasi

atas, dispilinkerjaterhadapkinerjakaryawanSPBUCocoPlaju 21.302.04 Palembang.

\section{KAJIAN PUSTAKA}

A. Landasan Teori

1. Motivasi

Menurut Robbins danJudge (2013) motivasiadalah proses yang menjelaskanintensitas, arah dan ketekunanseseorangindividuuntukmencapaitujuannya. Terdapattigakunciutama, yakni: intensitas, arah dan ketekuanan. Intensitasmenerangkanseberapakerasnyaseseorangberusaha.Itensitas yang 
tinggitidakakanmembawahasil yang diinginkankecualijikaupayaitudiarahkankesuatu yang menguntungkanorganisasi. Dengan kata lain,motivasiharusmemilikidimensiarah. Usaha untuktekunmajukearahtujuanorganisasiadalahusaha yang harusdipupuk. Akhirnya, motivasimemilikidimensiketekunan. Iniadalahukurantentangberapa lama seseorangdapatmempertahankanusahanya.Individu-individu yang termotivasiakantetapbertahan pada pekerjaanuntukmencapaitujuanmereka.

Hasibuan motivasiadalahpemberiandayapenggerakyangmenciptakankegairahankerjaseseorang, agar merekamaubekerjasama, bekerjaefektif, dan terintegrasidengansegaladayaupayanyauntukmencapaikepuasan.Dalamkaitannyadenganpe rusahaan, motivasimerupakan salah satuhalyangsangatpentingdiperhatikandalamorganisasiperusahaankarenahalinisangatmem pengaruhikinerjakaryawanyangada lingkunganperusahaantersebut.Motivasimerupakankondisiatauenergi yang menggerakandirikaryawan yang terarahatautertujuuntukmencapaitujuanorganisasiperusahaan. Sikap mentalkaryawan yang pro dan positifterhadapsituasikerjaitulah yang memperkuatmotivasikerjan yang untukmencapaikinerjamaksimal.

Berdasarkanpenjelasanteoridiatasdapatdisimpulkanyaitumotivasikerjamerupakan upayadorongan yang timbuldaridirisendiriuntukmelakukanpekerjaan dan menyalurkansemuakeahlian yang dimiliki agar tujuandariperusahaandapattercapai. Motivasiinipentingkarenadenganmotivasidiharapkansetiapindividukaryawanmaubekerjak eras dan antusiasuntukmencapaiproduktivitaskerja yang tinggi (sunyoto 2015). Dan juga memberikankeuntungankepadaorganisasiperusahaantersebut:
a. Dapatmeningkatkanproduktivitaskerjapegawai.
b. Dapatmendorongsemangat dan gairahkerjapegawai.
c. Dapatmempertahankankestabilanpegawai.
d. Dapatmeningkatkan moral dan kepuasankerjapegawai.
e. Dapatmenciptakansuasana dan hubungankerjapegawai.
f. Dapatmeningkatkankreativitas dan partisipasipegawai.
g. Dapatmeningkatkankesejahteraanpegawai.
h. Dapatmeningkatkankedisiplinan dan menurunkantingkatabsensipegawai.
i. Dapatmempertinggi rasa tanggungjawabpegawaiterhadaptugas-tugasnya.
j. Dapatmeningkatkanefisiensipenggunaanalat-alat dan bahanbaku.

\section{Faktor - Faktor Motivasi}

Swaminathan (2015) mengemukakanbahwaterdapatduafaktormotivasiyaitu:

a. Faktor Internal

Yaitu motivasiseseorangdipengaruhi oleh dalamdiriseseorang, misalnyajikaseorangkaryawan yang inginmendapatkannilai yang memuaskandalampeniaiankinerjaakanmengarahkankeyakinan dan perilakunyasedemikianrupasehinggamemenuhisyaratdaripenilaiankinerja yang telahditentukan. Hal iniakanberhubungandenganaspek-aspekataukekuatan yang adadalamdiriseseoranguntukmencapaisebuahtujuan,misalaspekefikasidiri.Selfefficacymerupakankepercayaanseseorangterhadapkeyakinandiri dan kemampuanyadalammelakukansuatupekerjaan,sehinggamemperolehsuatukeberhasilan.

b. Faktor Eksternal

Yaitu faktor yang berasaldariluarindividusepertifaktorkenaikanpangkat, penghargaan, gaji, keadaankerja, kebajikanperusahaan, sertapekerjaan yang mengandungtanggungjawab.

Karyawanakantermotivasiapabilaadadukungandarimanajemensertalingkungankerja yang kondusif yang pada gilirannyaberdampak pada kepuasankerja.

\section{Indikator-IndikatorMotivasi}


Indikator-indikatormenurut Teori Herzberg (2013) sebagaiberikut:

a. Gaji dan upah

Gajiatauupahadalahimbalan dibayarkankepadapekerjaatasusahayangdilakukan.

yang

b. Sistempengawasan

Sistempengawasanadalahkomponenatauelemenuntuk dalammenetapkanukurankinerjapengambilantindakan proses dapatmendukungpencapaianhasilyangdiharapkan.

yang

c. Kondisilingkungan

Kondisilingkungansituasikehidupansosial, psikologidan fisikdalamperusahaan yang berpengaruhterhadappekerjadalammelaksanakantugasnya.

d. Hubunganantarapribadi

Hubunganantarapribadiadalahsituasidimanahubungankomunikasi efektifdengansesamamanusia dan lingkungansekitar.

\section{DisiplinKerja}

Hasibuan

mengatakandisiplinadalahkuncikeberhasilansuatuperusahaandalammencapaitujuan-

tujuannya.

Disiplinmerupakanfungsipentingdalamsebuahorganisasikarenasemakinbaikkedisiplinanka ryawan, semakintinggiprestasikerja yang dapatdicapainya. Dalam arti sempit dan banyakdipakai,disiplinberartitindakan yang akandiambildenganpenyelesaiaanuntukmengkoreksiperilaku dan sikap yang salah pada sementarakaryawan. Sutrisno (2017) bentukdisiplin yang baikakantercermin pada suasanaseperti :

a. Tingginya rasa kepeduliankaryawanterhadappencapaiantujuanperusahaan.

b. Tingginyasemangat dan gairahkerja dan insiatif pada karyawandalammelakukanpekerjaan.

c. Besarnya rasa tanggungjawab para karyawanuntukmelaksanakantugasdengansebaik-baiknya.

d. Berkembangnya rasa memiliki dan rasa solidaritas yang tinggidikalangankaryawan.

e. Meningkatkanefisiensi dan produktivitaskerja pada karyawan.

Dari

pemahaman

di

atasdisimpulkanbahwadisiplinpegawaiadalahperilakuseseorang yang sesuaidenganperaturan, prosedurkerja yang adaataudisiplinkerjaadalahsikap, tingkahlaku dan perbuatan yang sesuaidenganperaturandariorganisasibaiktertulismaupuntidaktertulissertasanggupmenjala nkannyadantidakmengelakuntukmenerimasanksi-sanksinyaapabilaiamelanggartugas dan wewenang yang diberikankepadanya. MenurutRivai (2010) disiplinkerjaadalahsuatualat yang digunakan para manajeruntukberkomunikasidengankaryawanagarmerekabersediauntukmengubahsuatuper ilakusertasebagaisuatuupayauntukmeningkatkankesadaran dan kesediaanseseorangmentaatisemuaperaturanperusahaandannormanormasosialyangberlaku.

\section{Faktor-Faktor Disiplin}

Asumsi bahwapemimpinmempunyaipengaruhlangsungatassikapkebiasaan yang diperoleh, kebiasaanitu di tentukan oleh pemimpin, baikdenganiklimatausuasanakepemimpinanmaupunmelaluicontohdaripribadi. Karena itu, untukmendapatkandisiplinan yang baikmakapemimpinharusmemberikankepemimpinan yang baik pula. Singodimedjodalam Edy Sutrisno (2016) mengemukakanfaktor-faktor 
yang mempengaruhidisiplinkerjaadalah:

a. Besar kecilnyapemberiankompensasi

Para karyawanakanmemenuhisegalaperaturan yang berlaku, bilaiamerasamendapatkanjaminanbalasjasa yang setimpaldenganjerihpayahnya yang telahdikontribusikanbagiperusahaan.

b. Ada tidaknyaketeladananpemimpindalamperusahaan.

Keteladananpimpinan sangat pentingsekali, karenadalamlingkunganperusahaan, semuakaryawanakanselalumemerhatikanbagaimanapimpinandapatmenegakkandi siplindirinya dan bagaimanaiadapatmengendalikandirinyadariucapan, perbuatan dan sikap yang dapatmerugikanaturandisiplin yang sudahditetapkan.

c. Ada tidaknyaaturanpastidapatdijadikanpegangan

Pembinaandisiplintidakakandapatterlaksanadalamperusahaan,

bilatidakadaaturantertulis yang pastiuntukdapatdjadikanpeganganbersama.

d. Keberanianpemimpindalammengambilkeputusan

Denganadanyatindakanterhadappelanggarandisiplin, sesuaidengansangsiyangada, makasemuakaryawanakanmerasaterlindungi, dan dalamhatinyaberjanjitidakakanberbuathal yang serupa.

e. Ada tidaknyapengawasanpimpinan

Dalam setiapkegiatan yang dilakukan oleh perusahaanperluadapengawasan, yang akanmengarahkan para karyawan agar dapatmelaksanakanpekerjaandengantepat dan sesuaidengan yang telahditetapkan.

f. Ada tidaknyaperhatiankepada para karyawan

Karyawanadalahmanusia yang mempunyaiperbedaankarakterantara yang satudengan yang lain. Seorangkaryawantidakhanyapuasdenganpenerimaankompensasi yang tinggi dan pekerjaan yang menantang, tetapi juga merekamasihmembutuhkanperhatian yang besardaripimpinannyasendiri.

g. Diciptakankebiasaan-kebiasaan yang mendukungtegaknyadisiplin. Kebiasaankebiasaanpositifituantara lain:

1) Saling menghormati, bilabertemudilingkungankerja.

2) Melontarkanpujiansesuaidengantempat dan waktunya,sehinggaparakaryawanakanturutmerasabanggadenganpujianter sebut.

3) Saling mengikutsertakankaryawandalampertemuan-pertemuan, apalagipertemuanyangberkaitandengannasibdanpekerjaanmereka.

4) Memberitahubilainginmeninggalkantempatkepadarekankerja, denganmenginformasikankemanadanuntukurusanapa,walaupunkepadaba wahansekalipun.

\section{IndikatorDisiplin}

Indikator-indikatordisiplinmenurutRivai(2014)yaitusebagaiberikut:

a. Kehadiran.Halinimenjadiindikatoryangmendasaruntukmengukurkedisiplinan,dan biasanyakaryawanyangmemilikidisiplinkerjarendahterbiasauntukterlambatdalamb ekerja.

b. Ketaatan pada peraturankerja. Karyawan yang taat pada peraturankerjatidakakanmelalaikanprosedurkerjadanakanselalumengikutipedoma nkerjayangditetapkan oleh perusahaan.

c. Ketaatanpada standarkerja. Hal inidapatdilihatmelaluibesarnyatanggungjawabkaryawanterhadaptugas yang diamanahkankepadanya.

d. Tingkat kewaspadaantinggi. Karyawanmemilikikewaspadaantinggiakanselaluberhati-hati, penuhperhitungandanketelitiandalambekerja, 
sertaselalumenggunakansesuatusecaraefektifdan efisien.

e. Bekerjaetis. Beberapakaryawanmungkinmelakukantindakan yang tidaksopankepelangganatauterlibatdalamtindakanindisipliner,sehinggabekerjaetis sebagai salahsatuwujuddaridisiplinkerja.karyawan.

\section{Kinerja}

MenurutTorang(2016)kinerjaadalahkuantitasataukualiatshasilkerjaindividuatause kelompok di dalamorganisasidalammelaksanakantugaspokokdanfungsiyang berpedoman pada norma, standaroperasionalprosedur,kriteriadanukuranyangtelahditetapkanatauyangberlakudalamo rganisasi.

MenurutRivai (2011) kinerjamerupakanperilakuyang nyataditampilkansetiap orang sebagaiprestasikerja yang dihasilkan oleh karyawansesuaidenganperannyadalamperusahaan. SedangkanmenurutMangkunegara, (2016) istilahkinerjaberasaldari kata job performance atau actual performacse(prestasikerjaatauprestasisesungguhnyayang dicapaiseseorang.Dengankatalain kinerjaadalahtingkathasilkerja yang dicapaiseseorangdalammelaksanakanpekerjaandenganpersyaratanpersyaratanyangtelahditetapkan.Untukmengetahuitingkatkinerjakaryawan, perusahaanharusmelakukanpenilaiankerja yang akurat dan otentiktentangperilaku dan kinerjakaryawansehinggasemakinbesar pula potensinilainyabagiperusahaan. Kinerja mengacupada prestasipegawai yang diukurberdasarkanstandar yang ditetapkaninstansiatauperusahaan.

Afandi (2018) mengatakanbahwakinerjaadalahhasilkerja yang dapatdicapai oleh seseorangataukelompok orang dalamsuatuperusahaansesuaidenganwewenang dan tanggungjawab masing-masing dalamupayapencapaiantujuanorganisasisecara illegal, tidakmelanggarhukum dan tidakbertentangandengan moral dan etika. Kinerja adalahhasilatautingkatkeberhasilanseseorangsecarakeseluruhanselamaperiodetertentu di dalammelaksanakantugasdibandingkandenganberbagaikemungkinansepertistandarhasilke rja,targetatausasaranataukriteria yang telahditentukanterlebihdahulu dan telahdisepakatibersama.

Berdasarkanpengertian-

pengertiankinerjadaribeberapapendapatdiatas, dapatdisimpulkanbahwakinerjamerupakanh asilkerjabaikkualitasmaupunkuantitas yang telahdicapai oleh pegawai, dalammenjalankantugas-tugasnyasesuaidengantanggungjawab yang diberikan oleh perusahaan dan hasilkerjayang dicapaidisesuaikandenganstandarkinerjapegawai yang berlakudalamperusahaan.

\section{Faktor-Faktor Kinerja}

Motivasiberpengaruhterhadapkinerjakaryawankarenamemotivasiakanmendorong karyawanuntukmelaksanakanpekerjaansebaikmungkin. dapatdisimpulkanbahwasemakintinggitingkatmotivasiseorangkaryawanmakasemakinting gi pula kinerjanya. Sinungan (2018) menyebutkanbahwadisiplinmendorongkinerjaataudisiplinmerupakansaranapentinguntukm encapaikinerja. Dalamkondisiinimaka Tindakan yangseharusnyaperusahaanlakukanadalahmeningkatkankualitasperusahaandenganpeningk atandisiplinkerja.Kinerjakaryawandapatdilihatdaridisiplinkerja yang dilakukanseharhari.Selain itu, dengandisiplinkerja yang tinggidarikaryawan,makaakandapatmerasakanhasilkerja yang selamainiditekuni dan akanmampumencapaikinerja yangdiharapkanperusahaan. Sehinggadisiplinmenjadisalah satufaktorpenting yangharusmenjadiperhatiandalamsebuahperusahaan.

Mangkunegara mengatakankinerjaadalahhasilkerjasecarakualitasdankuantitasyangdicapaiolehseseorangk 
aryawandalammelaksanakantugasnyasesuaidengantanggungjawabyangdiberikankepadany a.

$$
\text { Dari pendapattentangfaktor-faktor yang mempengaruhikinerja }
$$
diatasdapatdilihatbahwamotivasidandisiplinkerjamerupakanbeberapafaktoryangmempeng aruhikinerja. Motivasi dan disiplinkerjamenjadidorongan yang kuatdaridalamdan luardirikaryawan yang membentukperilakukaryawandalamkinerjanya. Oleh karenaitupenelitimengangkatmasalahmotivasi dan disiplinkerjasebagaifaktorfaktoryangdapatmempengaruhikinerja.

\section{Indikator Kinerja}

MenurutMathisdanJackson(2016)adabeberapaindikatorkinerjaadalahsebagaiberik ut :

1) Kuantitashasilkerjaadalahjumlahdarihasilkerjayangdiselesaikanolehpegawai.

2) Kualitashasilkerjaadalahhasilkerjayangdicapaiolehpegawaiyangsesuaidengansyar at-syaratketentuan.

3) Ketepatanwaktuadalahketepatanwaktupegawaidalammenyelesaikanpekerjaanyan gtelahdiberikan.

4) Kehadiranditempatkerjaadalahkehadiranpegawaisesuaidenganaturanatau tatatertib yangberlakudalamorganisasi.

5) Sikapkooperatifadalahsikapbekerjasamadenganbaikdantaatsesuaidenganketentua ndalamorganisasi.

\section{B. PenelitianTerdahulu}

Tabel1. PenelitianTardahulu

\begin{tabular}{|l|l|l|l|l|l|}
\hline No & Peneliti & Tahun & \multicolumn{1}{|c|}{ Judul Peneliti } & \multicolumn{1}{|c|}{$\begin{array}{l}\text { Metode } \\
\text { analisis }\end{array}$} & \multicolumn{1}{|c|}{} \\
\hline 1 & Adiyanto & 2011 & $\begin{array}{l}\text { Pengaruh Motivasi Kerja } \\
\text { dan Kepemimpinan } \\
\text { Terhadap Kinerja Pegawai } \\
\text { Pada Badan Keluarga } \\
\text { Berencana dan } \\
\text { Pemberdayaan Perempuan } \\
\text { Kabupaten Menggarai- } \\
\text { Flores Nusa Tenggara } \\
\text { Timur }\end{array}$ & $\begin{array}{l}\text { Analisis } \\
\text { linear } \\
\text { berganda }\end{array}$ & $\begin{array}{l}\text { Motivasi } \\
\text { berpengar } \\
\text { uh positif } \\
\text { dan } \\
\text { signifikan } \\
\text { terhadap } \\
\text { kinerja } \\
\text { pegawai }\end{array}$ \\
\hline 2 & Prawaty & 2012 & $\begin{array}{l}\text { Pengaruh Disiplin Kerja } \\
\text { Dan Budaya Organisasi } \\
\text { Terhadap Kinerja } \\
\text { Karyawan Pabrik Minyak } \\
\text { Kayu Putih (PMKP) Di } \\
\text { krai purwodadi }\end{array}$ & $\begin{array}{l}\text { Analisis } \\
\text { regresi } \\
\text { linear } \\
\text { berganda }\end{array}$ & $\begin{array}{l}\text { Motivasi } \\
\text { berpengar } \\
\text { uh positif } \\
\text { dan } \\
\text { signifikan } \\
\text { terhadap } \\
\text { kinerja } \\
\text { karyawan }\end{array}$ \\
\hline 3 & $\begin{array}{l}\text { Rizon } \\
\text { Pranata }\end{array}$ & 2014 & $\begin{array}{l}\text { Pengaruh Motivasi Dan } \\
\text { Disiplin Kerja Terhadap } \\
\text { Kinerja Karyawan PT. } \\
\text { Adira Dinamika Multi } \\
\text { Finance Tbk.Arga } \\
\text { Makmur Bengkulu Utara }\end{array}$ & $\begin{array}{l}\text { Analisis } \\
\text { regresi } \\
\text { linear } \\
\text { berganda }\end{array}$ & $\begin{array}{l}\text { Motivasi } \\
\text { dan } \\
\text { disiplin } \\
\text { berpengar } \\
\text { uh negatif } \\
\text { terhadap } \\
\text { kinerja } \\
\text { karyawan }\end{array}$ \\
\hline
\end{tabular}




\begin{tabular}{|c|c|c|c|c|c|}
\hline 4 & $\begin{array}{l}\text { Prastika } \\
\text { Meilany }\end{array}$ & 2015 & $\begin{array}{l}\text { Pengaruh Displin Kerja } \\
\text { Terhadap Kinerja } \\
\text { Karyawan PT. Indah } \\
\text { Logistik Cargo Cabang } \\
\text { Pekanbaru }\end{array}$ & $\begin{array}{l}\text { Analisis } \\
\text { regresi } \\
\text { linear } \\
\text { sederhana }\end{array}$ & $\begin{array}{l}\text { Motivasi } \\
\text { berpengar } \\
\text { uh positif } \\
\text { dan } \\
\text { signifikan } \\
\text { terhadap } \\
\text { kinerja } \\
\text { karyawan }\end{array}$ \\
\hline
\end{tabular}

\section{KerangkaKonseptual Penelitian}

Kerangkaanalisisdalampenelitianinimerupakaninterpretasidarifaktorfaktoryangmempengaruhikinerja yangdigambarkanpenelitisebagaiberikut:

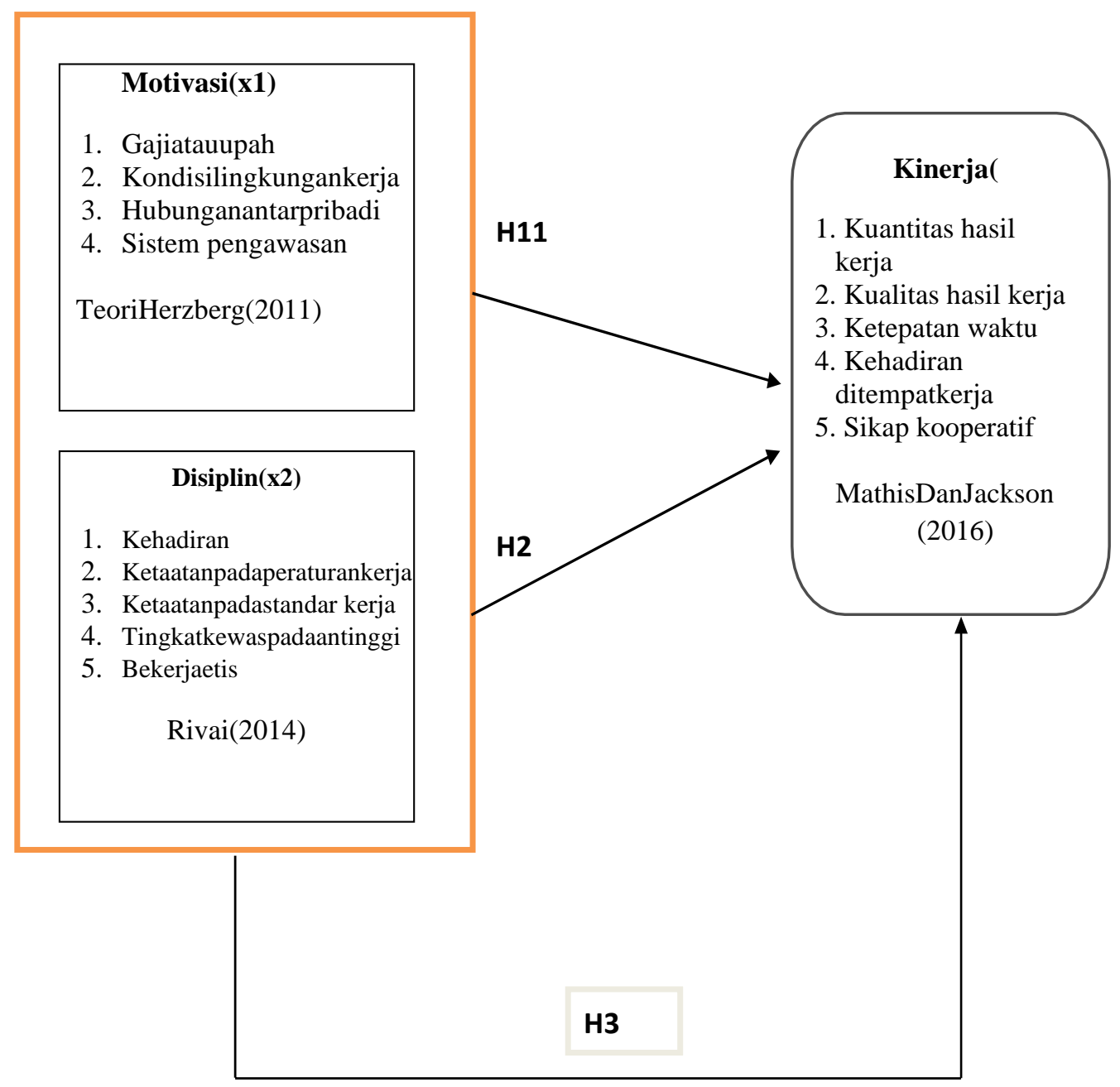




\section{Gambar 1. KerangkaKonseptual Penelitian}

Dari gambar 2.1 dijelaskanbahwamotivasi dan disiplinkerjasecarabersamasamamaupunparsialberpengaruhterhadapkinerjakaryawan. akanmendorongkaryawanuntukbekerjalebihgiat dan Sebaliknya, Motivasiyangtinggi, rendahakanmembuatkinerjakaryawantidakmaksimal.Sedangkanvariabeldisiplinkerjayangt inggiakandapatmeningkatkankinerjakaryawan, begitu juga sebaliknya. Dengandemikian, tinggirendahnyamotivasidandisiplinkerjaakanberpengaruhterhadapkinerjakaryawan.

\section{Hipotesis}

Sugiyono

hipotesisadalahjawabansementaraterhadaprumusanmasalahpenelitian.Dengandemikianhip otesisyangdiajukanolehpenulissebagaiberikut :

$\mathrm{H}_{1}=$

AdapengaruhmotivasiterhadapkinerjakaryawanSPBUCocoPlaju21.302.04Palemb ang.

$\mathrm{H}_{2}=$

AdapengaruhdisiplinkerjaterhadapkinerjakaryawanSPBUCocoPlaju21.302.04Pal embang.

$\mathrm{H}_{3}=$ AdapengaruhmotivasidandisiplinkerjaterhadapkinerjakaryawanSPBUCocoPlaju

21.302.04 Palembang.

\section{METODE PENELITIAN}

\section{A. MetodePengumpulan Data}

1. PopulasiPenelitian

Populasiadalah wilayah generalisasi yang terdiridariobjekatausubjek yang mempunyaikualitas dan karakteristiktertentu yang ditetapkan oleh penelitiuntukdipelajari dan kemudianditarikkesimpulanSugiyono (2012). Populasidalampenelitianiniadalah 35 karyawanSPBUCocoPlaju 21.302.04 Palembang.

2. Sampel

Sampel penelitianadalahsebagiandaripopulasi yang diambilsebagaisumber data dan dapatmewakiliseluruhpopulasi. Adapun penentuanjumlahsampel yang digunakan oleh penulisdalampenelitianiniadalahdenganmetodesensusberdasarkan pada ketentuan yang dikemukakan oleh sugiyono (2014) yang mengatakanbahwa“ teknikpenentuansampelbilasemuaanggotapopulasidigunakansebagaisampel. Hal iniseringdilakukanbilajumlahpopulasirelatifkecil". Metode penentuansampel yang digunakandalampenelitianiniadalahmetodesampeljenuh.Darihasilkriteriadiatasjumlahsam pelyangdigunakanadalah35orangpada SPBUCocoPlaju 21.302.04Palembang.

\section{B. Data yang digunakan}

1. Data Primer

Dalam penelitianini, data primer yang diperolehsecaralangsung di lapanganyangbersumberdariinformasi, denganmemakaiteknikpengumpulan databerupamembagikankuesionersertamelakukanobservasipengamatanlangsung)pada karyawandiSPBUCocoPlaju21.302.03Palembang.

2. Data sekunder

Data pendukungbagi data primer yang bahanliteratursepertidokumen-dokumen, catatan-catatan, sertaliteraturlainnyayangrelevandenganmasalahyangditeliti.

\section{Teknikpengumpulan data}


1. Wawancara

Wawancaramerupakan

proses memperolehpenjelasanuntukmengumpulkaninformasidenganmenggunakancaratanyajawa bbisasambilbertatapmukaataupuntanpatatapmuka,yaitumelaluimediatelekomunikasiantara pewawancaradenganorangyangdiwawancarai.

2. Observasi

Observasimerupakansuatukegiatanmendapatkaninformasi yang diperlukanuntukmenyajikangambaranrillsuatuperistiwaataukejadianuntukmenjawabpertan yaanpenelitian,untukmembantumengertiperilakumanusia, dan untukevaluasiyaitumelakukanpengukuranterhadapaspektertentumelakukanumpanbalikter hadappengukurantersebut.

3. StudiPustaka

Studipustakamerupakanmetodepengumpulan data yang dilakukandenganmembacabuku-buku, literatur, jurnal-jurnal, referensi yang berkaitandenganpenelitianini dan penelitianterdahulu yang berkaitandenganpenelitian yangsedangdilakukan

4. Kuesioner

Kuesioneradalahmetodepengumpulan dilakukandengancaramemberikanpertanyaanpertanyaankepadarespondendenganpanduankuesioner.

Kuesionerdalampenelitianinimenggunakanpertanyaanterbukadantertutup. Penelitian inisayamenggunakankuesionerdenganskalalikertsebagaiberikut :

\section{MetodeAnalisis}

1. AnalisisDeskriptif

MenurutSugiyono (2017) kegiatandalamanalisis data adalahmengelompokkan data berdasarkanvariabel dan jenisresponden, mentabulasi data berdasarkanvariabeldariseluruhresponden, menyajikan data tiapvariabel yang diteliti, melakukanperhitunganuntukmenjawabrumusanmasalah, melakukanperhitunganuntukmengujihipotesisyangtelahdiajukan.

Dalam metodeanalisis data inipenulismengambilanalisisdeskriptifyaituanalisis yang digunakanuntukmenganalisis data dengancaramendeskripsikanataumenggambarkandatayangtelahterkumpulsebagaimanaada nyatanpabermaksudmembuatkesimpulanyangberlakuuntukumumataugeneralisasi.

Dalamkegiatanmenganalisis data langkah-langkahyang penulislakukansebagaiberikut:

a. Membuatkuesioner

Penulismembuatkuesionerdalambentukpertanyaanataupernyataanyangakandiberi kan dan diisi oleh responden.Untukmendapatkantingkattanggapan yang tinggi, pertanyaan yang diajukansingkat danjelas, sertawaktu yang diperlukanuntukpengisiankuesionertidaklebihdari 15 menit.

b. Membagikandanmengumpulkankuesioner

Daftarkuesionerdisebarkebagian-bagianyangtelahditetapkan,setelahitu

di

kumpulkankembalikuesionertersebut yang telahdiisioleh responden.

c. Mencariskor

Untukmenentukannilaidarikuesionerpenelitimenggunakanskalalikert.

\section{UjiValiditas}

Ujivaliditasuntukmengetahuikelayakanbutir-

butirdalamsuatudaftar(konstruk)pertanyaandalammendefenisikansuatuvariabel.Menilaima sing-masing butirpertanyaandapatdilihatdarinilaicorrected item-total correlation. Nugroho (2010)mengatakansuatubutirpertanyaandikatakan valid jikanilair-hitung yang merupannilaidarinilaicorrected item-total correlation $n>$ dari $r$-tabel yang diperolehmelalui DF (Degree of freedom) Padatingkatkesalahan 5\%yaitu 0.304. Jadi 
hitung>dari0.304makasuatubutirpertanyaandikatakavalid.Untukmengujivalidtidaknyapert anyaandapatdilakukanmelalui program komputer (excel StatisticAnalysis\&SPSS)

3. Uji Realibilitas

Reliabilitasmerupakanukuransuatukestabilan konsistensirespondendalammenjawabhal dan konstrukpertanyaan yangmerupakandimensisuatuvariabel dan disusundalamsuatubentukkuesioner. Alatukur yang akandigunakanadalahCronbach alpa. ReliabilitassuatukonstrukvariabeldikatakanbaikjikamemilikinilaiCronbach alpa. 0,60.

4. UjiAnalisisRegresiBerganda

Regresidiartikansebagaisuatuteknikanalisis data yang digunakanuntukmencaripengaruhantaraduavariabelataulebih.Variabelyangdimaksudkanda lamhaliniadalahvariabelbebasyangbiasadisimbolkandenganXdanvariabelterikat yang disimbolkandengan Y. Analisisregresibergandadigunakanuntukmencaripengaruhantaraduaataulebihvariabelbeba sterhadapsatuvariabelterikat (Sugiyono, 2012). Menurut Sarwono (2011) analisisregresi linear bergandamengestimasikanbesarnyakoefisien-koefisienyangdihasilkanolehyang bersifat linear yang melihatkanduavariabelbebasuntukdigunakansebagaialatprediksibesarnyanilaivariabelterga ntung.Analisisregresibergandamerupakananalisisdatakuantitatifyangdigunakanuntukmenc aribesarhubungansecara linear antaraduaataulebihvariabelindependen $(\mathrm{x} 1, \mathrm{X} 2, \ldots . \mathrm{xn})$ denganvariabeldependen(Y).Ujiinidigunakanuntukmengetahuiapakahvariabelin denpenden $(\mathrm{x} 1, \mathrm{X}$, .....Xn)secarabersamasamaberpengaruhsecarasignifikanterhadapvariabeldependen $(\mathrm{Y})$. Persamaanregresibergandasebagaiberikut:

$$
\mathrm{Y}=\boldsymbol{\beta 0}+\boldsymbol{\beta} 1 \mathrm{X} 1+\boldsymbol{\beta} 2 \mathrm{X} 2+\mathrm{e}
$$

Keterangan:

$\mathrm{Y} \quad=$ YinerjaKaryawan (VariabelDependen)

$\beta 0=$ Konstanta

$\beta 1, \beta 2=$ KoefisienRegresi

$\mathrm{X} 1=$ Motivasi (Variabel Independen)

$\mathrm{X} 2=$ Disiplin (Variabel Independen)

$\mathrm{e} \quad=$ error

\section{UjiAsumsiKlasik}

Terdapatbeberapamacamasumsiyangharusdipenuhidalamanalisisregresi.

Sehinggapersamaan yang dihasilkanakan valid jikadigunakanuntukmemprediksi.Asumsiasumsitersebutantara lain:

a. UjiNormalitas

UjiKolmogorovSmirnov

merupakanpengujiannomalitasyangbanyakdipakai,terutamasetelahadanyabanyakprograms tatistikyangberedar.Kelebihandariujiiniadalahsederhanadantidakmenimbulkanperbedaanp ersepsi di antarasatupengamatdenganpengamat yang lain, yangseringterjadipadaujinormalitasdenganmenggunakangrafik.Konsepdasardariujinormal itasKolmogorovSmirnovadalahdenganmembandingkandistribusi data (yang akandiujinormalitasnya) dengandistribusinormal baku. Distribusi normal bakuadalah data yang telahditransformasikankedalambentukZ-Score dan diasumsikan normal. Jadi sebenarnya uji KolmogorovSmirnovadalah uji bedaantara data yang 
diujinormalitasnyadengan data normalbaku. Seperti pada uji bedabiasa, jikasignifikansi di bawah 0,05 berartiterdapatperbedaan yang signifikan, dan jikasignifikansi di atas 0,05 makatidakterjadiperbedaan yang sinifikan. Penerapan pada uji Kolmogorov Smirnov adalahbahwajikasignifkansi di bawah 0,05 berarti data yang akandiujimempunyaiperbedaanyangsignifikandengandata normalbaku,berartidatatersebuttidaknormal.

1) $\mathrm{P}<0,05$ - distribusidata tidaknormal

2) $P \geq 0,05-$ distribusitidaknormal

b. UjiMultikolinearitas

UjiMultikolinearitasdigunakanuntukmengujiapakahdalam

model regresiditemukanadaatautidaknyakorelasiantaravariabelbebas.Jikaterjadikolerasi,makadin amakanterdapatproblemmultikolinearitas.Modelregresiyangbaikseharusnyatidakterjadikol erasidiantaravariabelindependen.Jikaterbuktiadamultikolinearitas, sebaiknya salah satuindependen yang adadikeluarkandarimodel,lalupembuatanmodelregresidiulangkembali (Santoso, 2010). UntukmendeteksiadatidaknyamultikolinearitasdapatdilihatbesaranVariance Inflation Factor (VIF) dan Tolerance. Pedomansuatu model regresi yang bebasmultikolinearitasadalahmempunyaiangkatolerance mendekati 1. Batas VIF adalah 10, jikanilai VIF dibawah 10,makatidakterjadigejalamultikolinearitas (Gurjarati, 2012).MenurutSantoso(2012)rumusyangdigunakanadalahsebagaiberikut:

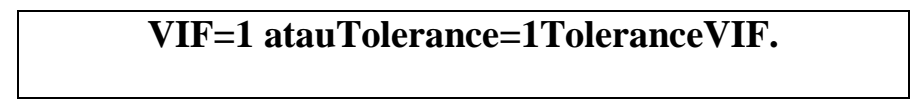

c. UjiHeteroskedastisitas

Uji heteroskedastisitasbertujuanuntukmengujiapakahdalamsebuah model regresi, terjadiketidaksamaanvariansatau residual darisatupengamatankepengamatan yang lain. Menurut Gujarati (2012) untukmengujiadatidaknyaheteroskedastisitasdugunakan uji-rank spearmanyaitudenganmengkorelasikanvariabelindependenterhadapnilaiabsolutdari

residual (error). Untukmendeteksigejala uji heteroskedastisitas, makadibuatpersamaanregresidenganasumsitidakadaheteroskedastisitaskemudianmenetuka nnilaiabsolut residual, selanjutnyamengregresikannilai absolute residual diperolahsebagaivariabeldependensertadilakukanregresidarivariabelindependen. Jika nilaikoefisienkorelasiantaravariabelindependendengannilaiabsolutdari residual signifikan, makakesimpulannyaterdapatheteroskedastisitas (variandari residual tidakhomogen).

\section{d. UjiKoefisienDeterminasi (Adjusted $R^{2}$ )}

Digunakanuntukmengukurseberapajauhkemampuan

dalammenerangkanvariabeldependen.

Nilaikoefisiendeterminasiterletakdiantaranoldansatu. Nilai $R^{2} \quad$ yang kecilberartikemampuanvariabel-variabel independent dalammenjelaskanvariabelvariabeldependensangatterbatas. Nilai $R^{2}$ yang mendekati satu berartivariabelvariabelindependenmemberikanhampirsemuainformasi dibutuhkanuntukmemprediksivariabel-variabeldependen.

6. UjiHipotesis

a. Ujit

Ujiinidigunakanuntukmengujisecaraparsialmasing-

masingvariabel.Hasilujitdapatdilihatpada

table coefficientspadakolomsig(significance).Jikaprobabilitasnilaitatausignifikansi<0,05,makad apatdikatakanbahwaterdapatpengaruhantaravariabelbebasterhadapvariabelterikatsecarapar 
sial. Namun, jikaprobabilitasnilai t atausignifikansi $>0,05$, makadapatdikatakanbahwatidakterdapatpengaruhyangsignifikan di antaramasingmasingvariabelbebasterhadapvariabelterikat (Sugiyono, 2011).

b. Uji F

Uji inidigunakanuntukmengetahuipengaruhvariabelbebassecarabersama-sama (simultan) terhadapvariabelterikat. Signifikan berartihubungan yang terjadidapatberlakuuntukpopulasi. Penggunaantingkatsignifikansinyaberagam, tergantungkeinginanpeneliti, yaitu 0,01 (1\%): 0,05 (5\%) dan 0,01 (10\%). Hasil uji F dilihatdalamtabel ANOVA dalamkolom sig. Sebagaicontoh, kitamenggunakantarafsignifikansi $\quad 5 \% \quad(0,05), \quad$ jikanilaiprobabilitas $<0,05$, makadapatdikatakanterdapatpengaruh yang signifikansisecarabersamasamaantaravariabelbebasterhadapvariabelterikat. Namun, jikanilaisignifikansi>0,05 makatidakterdapatpengaruh yang signifikansisecarabersamasamaantaravariabelbebasterhadapvariabelterikat.

\section{HASIL DAN PEMBAHASAN}

\section{A. Gambaran Umum Perusahaan}

PerusahaaniniyangberbentukperusahaanmitraPT.Pertaminayaitustasiunpengisianbahanbak $\operatorname{ar}(\mathrm{SPBU})$

yangmerupakanprasaranaumumyangdisediakanolehPT.Pertaminauntukmasyarakatluasgu namemenuhikebutuhanbahanbakar.PadaSPBUCocoPlaju

21.302.04 menjualbahanbakarjenispertalite, pertamax 92, pertamaxturbo, dexlite dan pertaminadex.StasiuniniberlokasidiJl.JendaralAhmadYaniNo.58-24,14Ulu, Kec.Seberang Ulu II, KotaPalembang, SumateraSelatan30111. YangmerupakananakperusahaandariPT.Pertamina retail (BUMN)yangbergerakdalambidangpemasaranprodukBBMPerusahaaninididirikanpadatan ggal 17agustus2009atasdasarkepadakomitmen Bersama untukbertujuanmenghadapiperubahanpasarretaildengannoregistrasibangunan danoperasidaripertaminadengannomor 21.302.04.

PerusahaanSPBUCoco no.21.302.04 merupakanbagiandarijaringanPT.Pertamina, dimanaterdapatklasifikasiSPBUyakniSPBUpertaminaWaydanPasti

Pas.SPBUinitermasukdalamkategoripertaminapastipas(padatahun 2009)yangmanatelahtersertifikasidapatmemberikanpelayananterbaikmemenuhistandard kelasdunia.

KonsumendapatmengharapkankualitasdankuantitasBBMterjaminkarenaSPBUPASTIPAS! Menggunakanalat-alatpengukurkualitasdankuantitaslebihakuratjuga

merupakanprosedurmonitoringyanglebihketat. Untukmenjaminketetapantakaran, SPBUmelakukantestketepatanvolumesecararutindenganbatastoleransiakurasilebihketatdar iSPBUbiasa.DinasMetrologiakanmelakukankalibrasiulangpompayangtelahmelewatibatast oleransiuntukmenjaminkualitasBBM, SPBUCocoPlajumelakukanpengujiankualitas3 kalilebihbanyakdariSPBUbiasa,jugadenganbatastoleransilebihketat.

Konsumenakanselaludisambutolehsenyum, salam, dansapaoperator.Untukmemastikanandamendapatkanvolumeyangakuratoperatorakanmen unjukkanpadaandamesinpompamenunjukkanangka0 (nol) sebelummulaipengisian. SedangkanuntukmendapatkansertifikasiPASTIPAS!,SPBUCocoPlajuinitelahmelakukanau ditsesuaidenganstandardpelayananyangtelahditetapkan olehPertamina. Auditinimencakupstandardpelayananjaminankualitasdankuantitas, kondisiperalatandanfasilitas, keselarasanformatfasilitas, danpenawaranprodukdanpelayanantambahan.SetelahmendapatkansertifikatPASTIPAS!,S PBUiniakantetapdiauditsecararutin. Jikatidaklolos, SPBUdapatkehilanganpredikatnyasebagaiSPBUPASTIPAS!. SPBUCoco

21.302.04yangmerupakansalahsatuperusahaanmitraPertaminayangbergerakdalambidangp 
endistribusianbahanbakarminyakkepadakonsumendanmemberikanpelayananprimajugame ngutamakanpadakepuasanpelanggan.

\section{B. DistribusiResponden}

\section{Berdasarkan Jenis Kelamin}

Berdasarkanjumlahkaryawan yang menjawabpertanyaan. Diperoleh data jeniskelaminkaryawansebagaimanadapatdilihardalamtabel 4.1 sebagaiberikut :

\section{Tabel 1. RespondenBerdasarkan Jenis Kelamin}

\begin{tabular}{|c|c|c|c|}
\hline No & Jenis kelamin & Jumlah & Presentase (\%) \\
\hline 1 & Laki-laki & 30 & $85,7 \%$ \\
\hline 2 & Perempuan & 5 & $14,3 \%$ \\
\hline & Jumlah & 35 & $100 \%$ \\
\hline
\end{tabular}

Sumber: pengolahan data SPSS VERSI 22

Berdasarkantabel 1 diatas, dapatdilihatbahwaberdasarkanjeniskelamindari 35 karyawan. Karyawanberjenislaki-lakiberjumlah 30 orang $(85,7 \%)$, dan jeniskelaminperempuansebanyak 5 orang $(14,3 \%)$, jadikaryawanterbanyak di SPBUCocoPlajuadalahlaki-laki.

\section{BerdasarkanUsia}

Berdasarkanusiakaryawan yang menjawabpertanyaandarikuesioner yang telahdibagikankepadakaryawan, diperoleh data antara lain mengenaibatasusiakaryawanmulaidari yang mudasampai yang tua, sebagaimanadapatdilihatdalamtabelberikut

Tabel 2. RespondenBerdasarkanusia

\begin{tabular}{|c|c|c|c|}
\hline No & Usia (tahun) & Jumlah (orang) & Presentase\% \\
\hline 1 & $18-\leq 25$ & 7 & $20,0 \%$ \\
\hline 2 & $25-\leq 30$ & 9 & $25,7 \%$ \\
\hline 3 & $30-\leq 35$ & 10 & $28,6 \%$ \\
\hline 4 & $\geq 35$ & 9 & $25,7 \%$ \\
\hline \multicolumn{2}{|c|}{ Jumlah } & 35 & $100 \%$ \\
\hline
\end{tabular}

Sumber: :pengolahan data SPSS VERSI 22

Berdasarkantabel 2 diatas, dilihatbahwaberdasarkanusiakaryawan yang berusia $18-\leq 25$ sebanyak 7 orang $(20,0 \%) 25-\leq 30$ sebanyak 9 orang $(25,7 \%), 30-\leq 35$ sebanyak 10 orang $(28,6 \%), \geq 35$ sebanyak 9 orang $(25,7 \%)$. Jadi karyawanterbanyakadalahberusia $30-\leq 35$ tahun.

\section{Berdasarkanpendidikan}

Pendidikan berdasarkanfaktorpentingdalammenjalankanperekrutankaryawanbaru. Berdasarkankaryawan yang menjawabpertanyaan, diperoleh data tentangpendidikanterakhirkaryawansebagaimanadapatdilihatdalamtabelberikutini :

Tabel 3. RespondenBerdasarkanpendidikan

\begin{tabular}{|c|c|c|c|}
\hline No & Tingkat pendidikan & Jumlah orang & Presentase $\%$ \\
\hline 1 & SMA & 32 & $85,7 \%$ \\
\hline 2 & Diploma & - & - \\
\hline 3 & S1 & 3 & $14,3 \%$ \\
\hline
\end{tabular}




\begin{tabular}{|c|c|c|}
\hline Jumlah & 35 & $100 \%$ \\
\hline
\end{tabular}

Sumber: pengolahan data SPSS VERSI 22

Berdasarkantabel3 diatas, dapatdilihatbahwaberdasarkankaryawanuntuk SMA/Sederajatsebanyak 32 orang $(85,7 \%)$, Diploma sebanyak 0 orang (0\%), SI sebanyak3orang $(14,3 \%)$, jadikaryawan yang terbanyakadalah yang berpendidikanSMA, dikarenakanSPBUmenganggaptingkatSmasudahpantasuntuk ditempatkandibagianpelayanan, sesuaidenganapa yang dibutuhkanperusahaan.

\section{Berdasarkan masa kerja}

Berdasarkanlamanya masa kerjakaryawanSPBUCocoplaju 21.302.04, diperoleh data lama kerjakaryawandapatdilihatdalamtabelberikut:

Tabel 4.RespondenBerdasarkan masa kerja

\begin{tabular}{|l|c|c|c|}
\hline No & Lama bekerja & Jumlah & Presentase $\%$ \\
\hline 1 & $0-\leq 2$ & 2 & $5,7 \%$ \\
\hline 2 & $2-\leq 4$ & 5 & $14,3 \%$ \\
\hline 3 & $4-\leq 6$ & 11 & $31,4 \%$ \\
\hline 4 & $6-\leq 8$ & 10 & $28,6 \%$ \\
\hline 5 & $8-\leq 10$ & 4 & $11,4 \%$ \\
\hline 6 & $\geq 10$ & 3 & $8,6 \%$ \\
\hline \multicolumn{2}{|l|}{ Jumlah } & 35 & $100 \%$ \\
\hline
\end{tabular}

Sumber:pengolahan data SPSS VERSI 22

Tabel 4 menunjukkanbahwaresponden masa kerja $0-\leq 2$ berjumlah 2 responden (5.7\%), responden masa kerja 2 - $\leq 4$ berjumlah 5 responden (14.3\%), responden masa kerja $4-\leq 6$ berjumlah 11 responden $(31.4 \%)$, responden masa kerja $6-\leq 8$ berjumlah 10 responden $(28.6 \%)$, responden masa kerja $8-\leq 10$ berjumlah 4 responden $(11.4 \%)$, dan responden masa kerja $\geq 10$ berjumlah 3 responden $(8.6 \%)$. Jadi karyawan yang terbanyakadalahresponden masa kerja $4-\leq 6$ berjumlah 11 responden $(31.4 \%)$.

\section{PEMBAHASAN}

1. Hasil Uji Validitas dan Reabilitas

a. Uji Validitas

1) Variabelmotivasi

Hasil pengolahan data untukmengetahuivariabel yang diteliti valid atautidak. Berikutpengujianvaliditas pada variabelmotivasi (X1). Hasil selengkapnyadapatdilihat pada table berikutini:

Tabel 5. Hasil Uji Validitas Motivasi X1

\begin{tabular}{|c|c|c|c|c|}
\hline \multirow{2}{*}{ No } & Keterangan & $\begin{array}{l}\text { Corrected } \\
\text { Item-Total } \\
\text { Correlation }\end{array}$ & $\begin{array}{l}\text { Rtabel } \\
(\mathbf{a = 5 \%})\end{array}$ & Hasil Validasi \\
\hline 1 & $\mathrm{X} 1 \mathrm{p} 1$ & 0.539 & 0,381 & Valid \\
\hline 2 & $\mathrm{X} 1 \mathrm{p} 2$ & 0.743 & 0,381 & Valid \\
\hline 3 & $\mathrm{X} 1 \mathrm{p} 3$ & 0.603 & 0,381 & Valid \\
\hline 4 & $\mathrm{X} 1 \mathrm{p} 4$ & 0.798 & 0,381 & Valid \\
\hline
\end{tabular}




\begin{tabular}{|l|l|l|l|l|}
\hline 5 & X1p5 & 0.655 & 0,381 & Valid \\
\hline 6 & X1p6 & 0.588 & 0,381 & Valid \\
\hline 7 & X1p7 & 0.435 & 0,381 & Valid \\
\hline 8 & X1p8 & 0.623 & 0,381 & Valid \\
\hline
\end{tabular}

Sumber: Pengolahan data SPSS Versi 22

Dari hasilanalisisdidapatnilaiCorected Item Total Correlation (rhitung) antaraskor item denganskor total. Nilai inikemudiandibandingkandengannilairtabel, rtabeldicari pada signifikasi 0,1 dengan uji 2 sisi dan jumlah data $(\mathrm{n})=35$, makadidapatrtabelsebesar 0,381. Berdasarkanhasilanalisisdidapatnilai Corrected Item Total Correlation (rhitung) untuksemua item lebihbesardari 0 , makadapatdisimpulkanbahwa item-item tersebutberkorelasisignifikandenganskor total (dinyatakan valid) sehinggadapatdisimpulkanbahwasemuabutir instrument tersebut valid.

2) VariabelDisiplin

Hasil pengolahan data untukmengetahuivariabel yang diteliti valid atautidak. Berikutpengujianvaliditas pada variabeldisiplin (X2). Hasil selengkapnyadapatdilihat pada table berikutini:

Tabel 6. Hasil Uji Validitas Disiplin X2

\begin{tabular}{|c|c|c|c|c|}
\hline No & Keterangan & $\begin{array}{c}\text { Corrected Item- } \\
\text { Total } \\
\text { Correlation }\end{array}$ & $\begin{array}{c}\text { Rtabel } \\
(\mathbf{a = 5 \% )}\end{array}$ & $\begin{array}{c}\text { Hasil } \\
\text { Validasi }\end{array}$ \\
\hline 1 & $\mathrm{X} 2 \mathrm{p} 1$ & 0.599 & 0,381 & Valid \\
\hline 2 & $\mathrm{X} 2 \mathrm{p} 2$ & 0.598 & 0,381 & Valid \\
\hline 3 & $\mathrm{X} 2 \mathrm{p} 3$ & 0.643 & 0,381 & Valid \\
\hline 4 & $\mathrm{X} 2 \mathrm{p} 4$ & 0.739 & 0,381 & Valid \\
\hline 5 & $\mathrm{X} 2 \mathrm{p} 5$ & 0.608 & 0,381 & Valid \\
\hline 6 & $\mathrm{X} 2 \mathrm{p} 6$ & 0.742 & 0,381 & Valid \\
\hline 7 & $\mathrm{X} 2 \mathrm{p} 7$ & 0.647 & 0,381 & Valid \\
\hline 8 & $\mathrm{X} 2 \mathrm{p} 8$ & 0.599 & 0,381 & Valid \\
\hline 9 & $\mathrm{X} 2 \mathrm{p} 9$ & 0.642 & 0,381 & Valid \\
\hline 10 & $\mathrm{X} 2 \mathrm{p} 10$ & 0.503 & 0,381 & Valid \\
\hline
\end{tabular}

Sumber: Pengolahan data SPSS Versi 22

Dari hasilanalisisdidapatnilaiCorected Item Total Correlation ( $\left.\mathrm{r}_{\text {hitung }}\right)$ antaraskoritem denganskor total. Nilai inikemudiandibandingkandengannilair tabel, $_{\text {, }}$

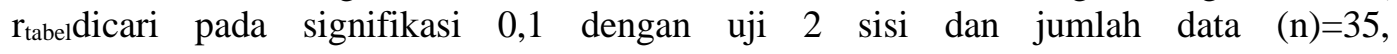
makadidapatr $\mathrm{tabel}_{\mathrm{S}} \mathrm{sebesar}$ 0,381. BerdasarkanhasilanalisisdidapatnilaiCorrected Item Total Correlation $\left(\mathrm{r}_{\text {hitung }}\right.$ ) untuksemua item lebihbesardari 0,381 makadapatdisimpulkanbahwa item-item tersebutberkorelasisignifikandenganskor total (dinyatakan valid) sehinggadapatdisimpulkanbahwasemuabutir instrument tersebut valid dan dapatdiikutsertakankepenelitianselanjutnya.

3) Variabel Kinerja Karyawan

Hasil pengolahan data untukmengetahuivariabel yang diteliti valid atautidak. Berikutpengujianvaliditas pada variabelkinerjakaryawan (Y). Hasil selengkapnyadapatdilihat pada table berikutini:

Tabel 7. Hasil Uji Validitas Kinerja Karyawan Y

\begin{tabular}{|c|c|c|c|c|}
\hline No & $\begin{array}{c}\text { Keteranga } \\
\mathbf{n}\end{array}$ & $\begin{array}{c}\text { Corrected Item- } \\
\text { Total }\end{array}$ & $\begin{array}{c}\text { Rtabel } \\
(\mathbf{a}=\mathbf{5 \%})\end{array}$ & Hasil Validasi \\
\hline
\end{tabular}




\begin{tabular}{|c|c|c|c|c|}
\hline & & Correlation & & \\
\hline 1 & Yp1 & 0.608 & 0,381 & Valid \\
\hline 2 & Yp2 & 0.608 & 0,381 & Valid \\
\hline 3 & Yp3 & 0.626 & 0,381 & Valid \\
\hline 4 & Yp4 & 0.749 & 0,381 & Valid \\
\hline 5 & Yp5 & 0.647 & 0,381 & Valid \\
\hline 6 & Yp6 & 0.742 & 0,381 & Valid \\
\hline 7 & Yp7 & 0.630 & 0,381 & Valid \\
\hline 8 & Yp8 & 0.608 & 0,381 & Valid \\
\hline 9 & Yp9 & 0.627 & 0,381 & Valid \\
\hline 10 & Yp10 & 0.491 & 0,381 & Valid \\
\hline
\end{tabular}

Sumber: Pengolahan data SPSS Versi 22

Dari hasilanalisisdidapatnilaiCorected Item Total Correlation $\left(\mathrm{r}_{\text {hitung }}\right)$ antaraskor item denganskor total. Nilai inikemudiandibandingkandengannilai $r_{\text {tabel, }} r_{\text {tabel }}$ dicari pada

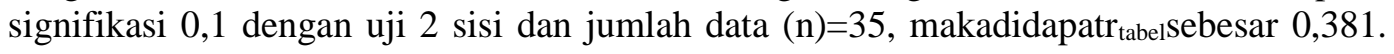
BerdasarkanhasilanalisisdidapatnilaiCorrected Item Total Correlation $\left(\mathrm{r}_{\text {hitung }}\right)$ untuksemua item lebihbesardari 0,381 makadapatdisimpulkanbahwa item-item tersebutberkorelasisignifikandenganskor total (dinyatakan valid) sehinggadapatdisimpulkanbahwasemuabutir instrument tersebut valid.

\section{b. Uji Reabilitas}

Metode pengujianreabilitas yang digunakandalampenelitianiniadalah AlphaCronbach. Standar yang digunakandalammenentukan reliable dan tidaknyasuatu instrument penelitianadalahperbandinganantara $\mathrm{r}_{\text {-hitungdengan }} \mathrm{r}_{\text {-tabel }}$ pada tarafsignifikansi 5\%. Apabiladilakukanpengujianreabilititasdenganmetode Alpha-Cronbach, makanilai $\mathrm{r}$ hitungdiwakili oleh nilai Alpha. Kemudianuntukmenentukan data realibelatautidakmenggunakanabalisa SPSS versi 22. Hasil pengolahantersebutdapatdilihat pada table berikut:

Tabel 8. Hasil Uji Reabilitas

\begin{tabular}{|c|c|c|c|}
\hline Item & $\begin{array}{c}\text { Cronbach's } \\
\text { Alpha }\end{array}$ & StandarReabilititas & $\begin{array}{c}\text { Hasil } \\
\text { Reabilitas }\end{array}$ \\
\hline $\mathrm{X} 1$ & 0.865 & 0,60 & Valid \\
\hline $\mathrm{X} 2$ & 0888 & 0,60 & Valid \\
\hline $\mathrm{Y}$ & .0888 & 0,60 & Valid \\
\hline
\end{tabular}

Sumber: Pengolahan data SPSS Versi 22

Berdasarkan table diatasbahwaseluruhnilai Cronbach's alpha melebihistandarreabilitas. Karena nilaiseluruh Cronbach's Alpha lebihbesardaripada 0,6 makadapatdisimpulkanbahwaseluruhintrumendinyatakanrealibel. 


\section{Uji Asumsi Klasik}

a. Uji Normalitas

Jika nilaisignifikan (p-value) >0,005 maka Ho diterima yang artinyanormalitasterpenuhi. Hasil PengujianNormalitas Residual dapatlilihat pada Tabel 1.1 .

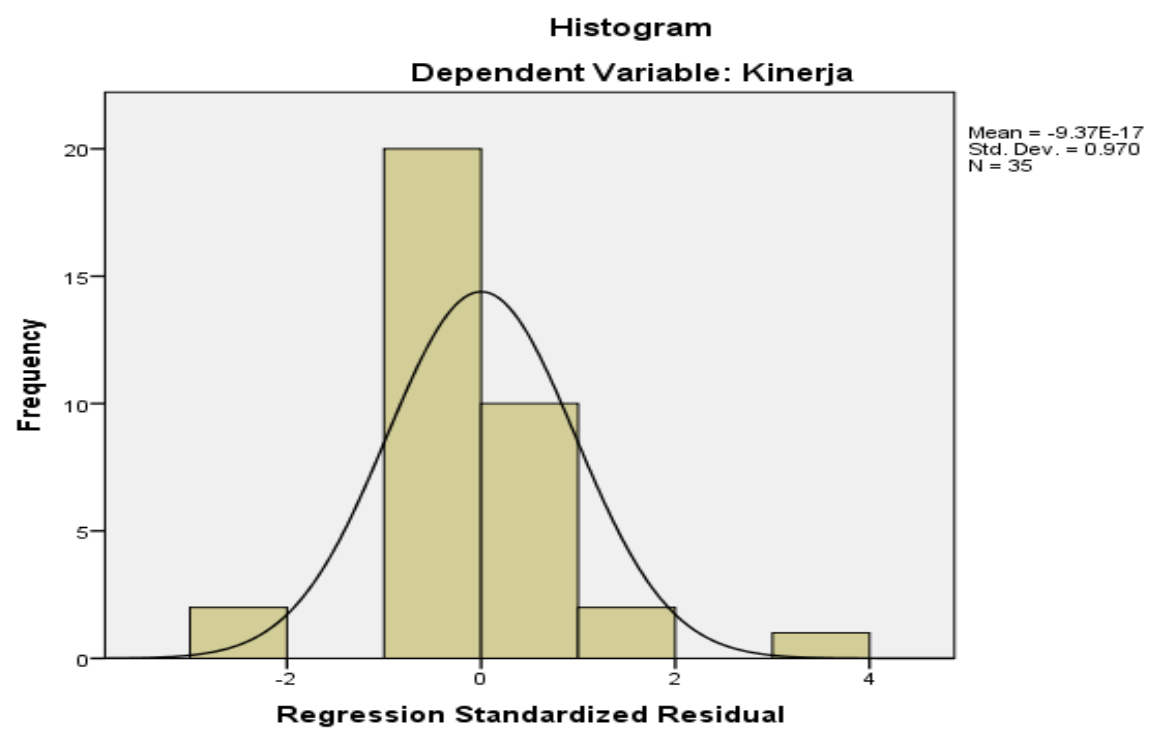

\section{Gambar 2. Hasil Uji Normalitas}

Berdasarkangambar 2hasil uji normalitas, dapatdiketahuibahwa output yang dihasilkannilai sig lebihbesardariyaitu $0,970>0,05$ yang berarti data berdistribusi normal residual terpenuhi.

\section{b. Uji Multikolinearitas}

Untukmendeteksiadatidaknyamultikolinearitasdigunakan variance inflation faktor $\mathrm{VIF}<10$, Maka terima Ho yang artinyapersamaanregresi linier bergandatidakterjadikasusmultikolinearitas. Hasil pengujianmultikolinieritasditunjukkan pada tabel

Dari tabel 2 di bawahinidapatdilihatbahwanilai Tolerance untukvariabelmotivasi(X1) dan disiplin (X2) adalah 0,71 lebihbesardari 0,1. Semantaranilai VIF untukvariabelmotivasi (X1) dan disiplin (X2) adalah 4.131<10. Maka mengacu pada dasarpengambilankeputusandalam uji multikolinearitasdapatdisimpulkanbahwatidakterjadigejalamultikolinearitasdalam model regresi.

Tabel 9

\section{Uji Multikolinearitas}

\section{Coefficients $^{\mathrm{a}}$}




\begin{tabular}{|c|c|c|c|c|c|c|c|c|}
\hline & & \multicolumn{2}{|c|}{$\begin{array}{c}\text { Unstandardized } \\
\text { Coefficients }\end{array}$} & \multirow{2}{*}{$\begin{array}{c}\text { Standardized } \\
\text { Coefficients } \\
\text { Beta }\end{array}$} & \multirow[b]{2}{*}{$t$} & \multirow[b]{2}{*}{ Sig. } & \multicolumn{2}{|c|}{$\begin{array}{c}\text { Collinearity } \\
\text { Statistics }\end{array}$} \\
\hline Model & & B & $\begin{array}{l}\text { Std. } \\
\text { Error }\end{array}$ & & & & $\begin{array}{c}\text { Toleranc } \\
\mathrm{e}\end{array}$ & VIF \\
\hline 1 & (Constant) & .714 & 683 & & 1.044 & .304 & & \\
\hline & Motivasi & .004 & .074 & .003 & .054 & .957 & .071 & 4.131 \\
\hline & $\begin{array}{c}\text { DisiplinKer } \\
\text { ja }\end{array}$ & 981 & .061 & .992 & 16.023 & .000 & .071 & 4.131 \\
\hline
\end{tabular}

a. Dependent Variable: Kinerja

\section{c. Uji Heteroskedastisitas}

Jika nilaisignifikan ( $p$-value) semuavariabelindependen>0,05 maka Ho diterima yang artinyavarian residual homogen (tidakterjadikasusheteroskedastisitas). Hasil daripengujianheteroskedasitasdapatdilihat pada tabel 1.3

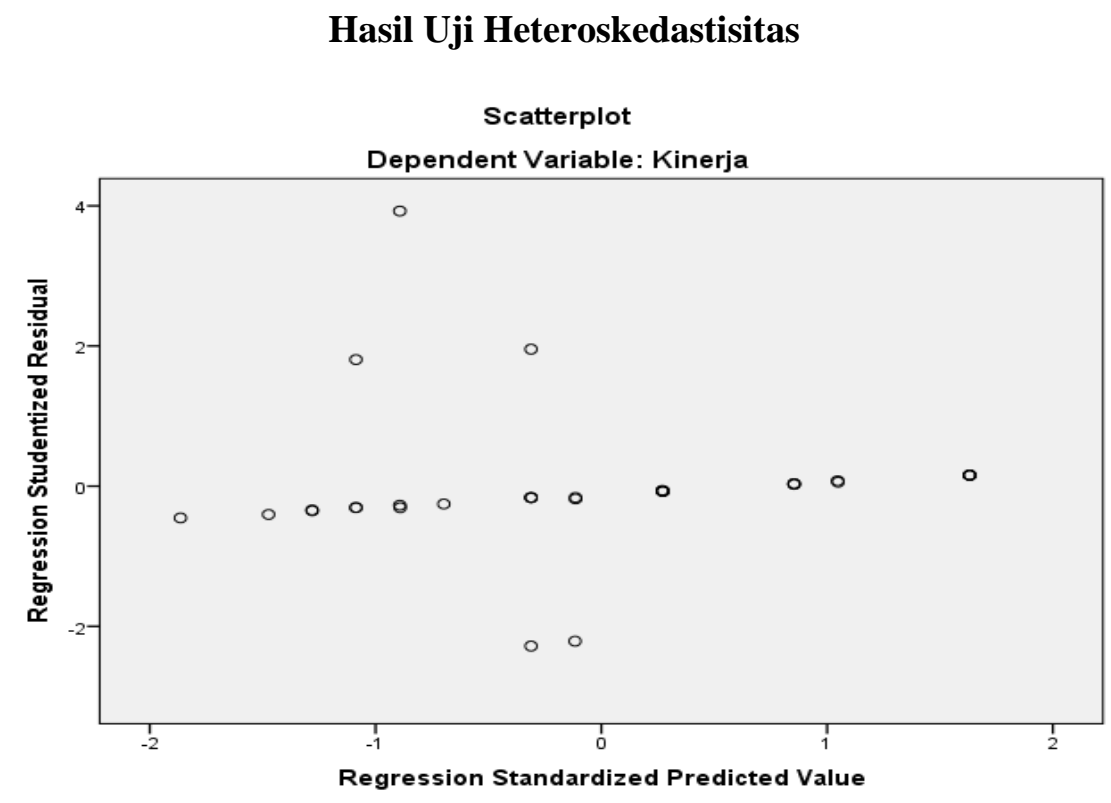

Gambar 3. Hasil Uji Heterokedastisitas

Tabel 1.3 menunjukkanhasilpengujianheteroskedastisitas. Dari hasiltersebut, diketahuibahwanilaisignifikansiuntuksemuavariabelbebaslebihbesardari 0,05 (alpha 5\%), yang berartitidakadapengaruhvariabeldependen (hargamutlak residual) terhadapX1 dan $\mathrm{X} 2$. Karena variabel X1 dan X2 keduanyatidakadapengaruhterhadaphargamutlak residual makaterima

Ho.

Sehinggadapatdisimpulkanbahwatidakterjadiheteroskedastisitasterpenuhi.

\section{AnalisiRegresi Linear Berganda}

Analisisregresi

bergandainidigunakanuntukmengetahuipengaruhantaravariabelmotivasi dan disiplinkerjaterhadapkinerjakaryawan. Hasil analisitersebutdapatdilihat pada tabelberikutini: 
Coefficients $^{\mathrm{a}}$

\begin{tabular}{|c|c|c|c|}
\hline \multirow[b]{2}{*}{ Model } & \multicolumn{2}{|c|}{ Unstandardized Coefficients } & $\begin{array}{c}\text { Standardized } \\
\text { Coefficients }\end{array}$ \\
\hline & B & Std. Error & Beta \\
\hline (Constant) & .714 & .683 & \\
\hline $\begin{array}{c}\text { Total_X1 } \\
\text { (Motivasi) }\end{array}$ & .004 & .074 & .003 \\
\hline Total_X2 & 981 & .061 & 992 \\
\hline
\end{tabular}

a. Dependent Variable: Total_Y

Dari hasilperhitungantabelmelalui program

SPSS, diperolehpersamaanregresibergandadapatdituliskansebagaiberikut:

$$
\mathrm{Y}=0,714+0,004 X 1+0,981 X_{2}+e
$$

Berdasarkanfungsipersamaanregresi linier bergandamakadiperolehnilaikonstantasebesar 0.714 menyatakanbahwamotivasi dan disiplintidakmengalamiperubahanmakaskorkinerjakaryawanadalah 0.714 .
a. Koefisienregresi
$\left(b_{1}\right)$,
motivasi
$\left(\mathrm{X}_{1}\right)$
sebesar
0.004

bernilaipositifmenyatakanbahwasetiappenambahanskormotivasi,

akanmeningkatkanskorkinerjakaryawansebesar 0.004 denganasumsiskordisiplin $\left(\mathrm{X}_{2}\right)$ tetap/konstan.

$\begin{array}{llllll}\text { b. Koefisienregresi } & \left(\mathrm{b}_{2}\right), \quad \text { disiplin } & \left(\mathrm{X}_{2}\right) & \text { sebesar } & 0.981\end{array}$ bernilaipositifmenyatakanbahwasetiappenambahanskordisiplin yang semakinbaikakanmeningkatkanskorkinerjakaryawansebesar 0.981 denganmenjagaskormotivasi $\left(\mathrm{X}_{1}\right)$ tetap/konstan.

\section{Uji t (parsial)}

Uji $\mathrm{t}$ (parsial) bertujuanuntukmengetahuiapakahvariabelmotivasi dan disiplinsecaraparsialberpengaruhterhadapvariabelkinerjakaryawan. Adapun hasilnyadapatdilihat pada tabelberikutini:

Coefficients $^{\mathrm{a}}$

\begin{tabular}{|c|c|c|c|c|c|}
\hline & \multicolumn{2}{|c|}{$\begin{array}{c}\text { Unstandardized } \\
\text { Coefficients }\end{array}$} & $\begin{array}{c}\text { Standardized } \\
\text { Coefficients }\end{array}$ & & \\
\cline { 2 - 4 } Model & $\mathrm{B}$ & Std. Error & Beta & $\mathrm{T}$ & Sig. \\
\hline $\begin{array}{c}\text { (Constant) } \\
\text { Total_X1 } \\
\text { (Motivasi) }\end{array}$ & .714 & .683 & & 1.044 & .304 \\
\hline $\begin{array}{c}\text { Total_X2 } \\
\text { (Disiplin) }\end{array}$ & .904 & .074 & .003 & .054 & .957 \\
\hline
\end{tabular}

a. Dependent Variable: Total_Y

Sumber: Hasil pengolahan data SPSS, versi 22

Berdasarkanhasilperhitungantabeldiatasdapatdiinteprestasikanbahwa:

a. Motivasi

$\left(\mathrm{X}_{1}\right)$

mempunyaihubunganpositifatausearah, haliniberartibilamotivasiditingkatkan, makakinerjakaryawan juga meningkat. Hal inidibuktikandengannilai sig t 0,957>0,05 makadapatdisimpulkan Ho ditolak Ha diterimaartinyabahwamotivasitidaksecaraparsialberpengaruhterhadapkinerjakarya wan. 
b. Disiplin $\quad\left(\mathrm{X}_{2}\right) \quad$ mempunyaihubunganpositifatausearah, haliniberartibiladisiplinditingkatkan, makakinerjakaryawan juga meningkat. Hal inidibuktikandengannilai sig $0,000<0,05$ maka Ho ditolak dan $\mathrm{Ha}$ diterimaartinyaadapengaruhdisiplinterhadapkinerjakaryawan.

\section{Uji F (simultan)}

UjiF (simultan) bertujuanuntukmengetahuiapakahvariabelmotivasi dan disiplin (secarasimultan) berpengaruhterhadapvariabelkinerjakaryawan. Adapun hasilnyadapatdilihat pada table 4.9 berikutini:

Tabel 10 Uji F

\begin{tabular}{|l|c|c|c|c|c|}
\hline \multicolumn{7}{|c|}{ ANOVA $^{\text {a }}$} \\
\hline Model & $\begin{array}{c}\text { Sum of } \\
\text { Squares }\end{array}$ & Df & Mean Square & F & Sig. \\
\hline Regression & 874.224 & 2 & 437.112 & 1825.684 & $.000^{\text {b }}$ \\
\hline Residual & 7.662 & 32 & .239 & & \\
\hline Total & 881.886 & 34 & & & \\
\hline $\begin{array}{l}\text { a. Predictors: (Constant), Total_X1, Total_X2 } \\
\text { b. Dependent Variable: Total_Y }\end{array}$
\end{tabular}

Berdasarkan table 4.9 dapatdilihatbahwanilai $F_{\text {hitung diperolehsebesar } 1825.684}$ lebihbesardari $\mathrm{F}_{\text {tabel }}(0.000)$, halini juga diperkuatdengannilaitarafsignifikansebesar 0,000 atausignifikasi yang diperolehlebihkecildari $\alpha=0,05$ artinya Ho ditolak dan Ha diterima. Maka dapatdisimpulkanbahwamotivasi dan disiplinkerjaberpengaruh dan signifikanterhadapkinerjakaryawan.

\section{Uji Determinasi}

Uji

koefisiendeterminaninidigunakanuntukmengetahuiseberapabesarseberapabesarsumbanga nvariabelbebas, yaitumotivasi dan disiplinkerjasecarasimultanterhadapkinerakaryawan pada SPBUCocoPlaju 21.302.04 Palembang.

Tabel 11. Hasil Uji Determinasi Model Summary ${ }^{b}$

\begin{tabular}{|l|r|r|r|r|r|}
\hline Model & \multicolumn{1}{|c|}{$\mathrm{R}$} & R Square & \multicolumn{1}{c|}{$\begin{array}{c}\text { Adjusted R } \\
\text { Square }\end{array}$} & $\begin{array}{c}\text { Std. Error of the } \\
\text { Estimate }\end{array}$ & Durbin-Watson \\
\hline 1 & $.996^{\mathrm{a}}$ & .991 & .991 & .48931 & 1.412 \\
\hline
\end{tabular}

a. Predictors: (Constant), DisiplinKerja, Motivasi

b. Dependent Variable: Kinerja

Berdasarkanhasilperhitungantabeldiatasdeganmenggunakan program SPSS dapat di interprestasikanbahwa Angka Adjusted $\mathrm{R}$ Square sebesar 0,991 memberikanmaknabahwavariabelMotivasi Dan Disiplinkerjahanyamampumenjelaskanperubahanterhadapvariabelkinerjakaryawansebesar $99,1 \%$ sedangkansisanya $0,9 \%$ dijelaskan oleh variabel lain yang tidaktermasukdalampenelitian 


\section{KESIMPULAN}

Berdasarkan hasil penelitian yang telah diuraikan dalam bab sebelumnya, dapat dibuat kesimpulan sebagai berikut:

1. Motivasi dan disiplin kerja secara simultan berpengaruh terhadap karyawan SPBU Coco Plaju 21.302.04 palembang yang ditunjukan dengan nilai $\mathrm{F}_{\text {hitung }} 1825.684$ yang lebihbesardariF $F_{\text {tabel }}(0.000)$, kemudiandengantingkatsignifikansi 0,000 lebihkecildaritingkatprobabilitas alpha 0,05, yang berartihipotesisnol (Ho) ditolakdanhipotesisalternatif (Ha) diterima, makamotivasidandisiplinberpengaruhsignifikanterhadapkinerjakaryawanSPBU Coco Plaju 21.302.04 palembang.

2. MotivasikaryawanSPBU Coco Plaju 21.302 .04 palembangberpengaruhpositifdansignifikanterhadapkinerjakaryawan yang ditunjukandarihasilkoefisienregresibergandasebesar $\quad 0,004$ dengantingkatsignifikansi 0,074 .

3. DisiplinkaryawanSPBU Coco Plaju 21.302 .04 palembangberpengaruhpositifdansignifikanterhadapkinerjakaryawan yang ditunjukandarihasilkoefisienregresibergandasebesar $\quad 0,981$ dengantingkatsignifikansi 0,061.KinerjakaryawanSPBU Coco Plaju 21.302.04 palembangtergolongsangattinggi.

\section{DAFTAR PUSTAKA}

Anderson, R. E., \& Swaminathan, S. 2015. Customer satisfaction and loyalty ine-markets: A PLS path modeling approach. Journal of Marketing Theory and Practice, Vol. 19, No. 2, 221-234.

A.A. Anwar Prabu Mangkunegara. 2016. Manajemen Sumber DayaManusiaPerusahaan.Bandung:PT. RemajaRosdakarya.

A.A. AnwarPrabuMangkunegara.2017.ManajemenSumberDayaManusiaPerusahaan.PT. RemajaRosdakarya.Bandung.

A.A Anwar Prabu Mangkunegara. 2012. ManajemenSumber Daya Manusia.Bandung:PT. RemajaRosdakarya.

AnnisaPratiwi, IsmiDarmastuti.

2014. PengaruhmotivasidandisiplinkerjaterhadapkinerjakaryawanPT.adiradinamikamult ifinance. tbk.Argamakmur.

Afandi,P.2018.ManajemenSumberDayaManusia;Teori,KonsepdanIndikator,edisi 1. ed. Zanafa, Pekanbaru.

Agung, Bhuono Nugroho. 2010. Strategi Jitu Memilih Metode StatistikPenelitian Dengan SPSS.Penerbit CV. Andi Offset Yogyakarta.

Bangun, Wilson.2012. ManajemenSumberDayaManusia.Jakarta:Erlangga.

BintorodanDaryanto. 2017.ManajemenPenilaianKinerjaKaryawanCetakan 1.Yogyakarta:GavaMedia.

Edy, Sutrisno. 2011. ManajemenSumberDaya Manusia. Jakarta: Kencana.

Ghozali,Imam. 2011.AplikasiAnalisisMultivariateDenganProgramSPSSSemarang:Badan Penerbit UniversitasDiponegoro.

Ghozali,Imam. 2011.AplikasiAnalisisMultivariateDenganProgramIBMSPSS17. CetakanKelima. Semarang:BadanPenerbitUniversitasDiponegoro

Ghozali,Imam. 2018.AplikasiAnalisisMultivariateDenganProgramIBMSPSS25.Badan PenerbitUniversitasDiponegoro. Semarang.

Ghozali, Imam.2011.

AplikasiAnalisisMultivariatedenganProgramIBMSPSS19.Semarang:Badan PenerbitUniversitasDiponegoro.

Gurjarati. 2012. Dasar-dasar ekonometrika. Buku 2 edisi 5.Jakarta:SalembaEmpat 
Herzberg, Frederick. 2013. Motivation-Hygiene Theory and Job Satisfaction in TheMalaysian Retail Sector: The Mediating Effect OfLove Money. Sunway University Malaysia: Teck Hang Tan and Amna Waheed

Hasibuan, MalayuS.P.2015.ManajemenSumberDayaManusia,Penerbit:

PT.BumiAksara, Jakarta.

Hasibuan, Malayu S.P. 2016. ManajemenSumber Daya Manusia.EdisiRevisi.Jakarta:Penerbit PT. Bumi Aksara.

Kasmir.2016.ManajemenSumberDayaManusia. TeoridanPraktik.Depok:PT RajagrafindoPersada.

M.B,Alim.2013.Teori HerzbergdanKepuasanKerjaKaryawan.Disadurpada11November 2013.

Mathis Robert L dan John H. Jackson. 2016. ManajemenSumber DayaManusia.Buku1. AlihBahasa:JimmySadelidanBayu.PrawiraHie,SalembaEmpat.Jakarta.

Muchdarsyah, Sinungan. 2018. ProduktivitasApa dan Bagaimana. Jakarta:BumiAksara.

Robbins, Stephen P \& Judge, Timothy A. 2013.Organizational Behavior Edition 15. New Jersey: Pearson Education.

Rizon, Pranata. 2014. Pengaruh Motivasi dan DisiplinKerjaTerhadap KinerjaKaryawan PT.Adira Dinamika Multi Finance TBK.Arga Makmur Bengkulu Utara.

Rivai. 2014. Kepemimpinan dan Perilaku Organisasi. Jakarta: PT. RajaGrafindoPersada

Rivai, Veithzal dan Sagala. 2013. Manajemen Sumber Daya Manusia untuk

Perusahaan dariTeorikePraktik.Jakarta:PTRaja Grafindo.

Rivai, Veitzal dan Deddy Mulyadi. 2010.KepemimpinanPerilakuOrganisasiJakartaRajawali Pers.

Rivai, Veitzal dan Ella Jauvani. 2011. Manajemen Sumber Daya ManusiauntukPerusahaan:PT.RajaGrafindoPersada.

Rikhayati. 2018.PengaruhMotivasi dan DisiplinTerhadap Kinerja Pegawai(studi pada PT.Telekomunikasiindonesia, Tbk wilayah telkompekalongan)

Robbins, Stephen P \&Judge, Timothy A. 2013. Organizational BehaviorEdition 15. NewJersey:Pearson Education.

Sastrohadiwiryo.2012.ManajemenTenagaKerjaIndonesia. Jakarta:PT.BumiAksara.

Sunyoto, Danang. 2015. Manajemen dan PengembanganSumber Daya Manusia(CetakanPertama).Yogyakarta:CAPS(CenterforAcademicPublishingServ ice).

Sugiyono. 2012. Metode Penelitian Pendidikan.Bandung: Alfabeta.

Sugiyono. 2010. Metode Penelitian KuantitatifKualitatif\& RND.Bandung:Alfabeta.

Sugiyono. (2012). Metode Penelitian Bisnis. Bandung: Alfabeta

Sugiono. 2010.StatistikaUntukPenelitian.Bandung:Alfabeta.

Sugiyono.2013.MetodePenelitianPendidikan(PendekatanKuantitatif,Kualitatifdan R\&D. Bandung:Alfabeta

Sugiyono.2017.MetodePenelitianKuantitatif,Kualitatif,danR\&D.Bandung: Alfabeta

Sugiyono.

2017.MetodePenelitianKualitatif:Untukpenelitianyangbersifat:eksploratif,enterpr etif, interaktif,dan konstruktif.Bandung:Alfabeta.

Santoso,Singgih.2012.StatistikParametik.Jakarta:PT. GramediaPustaka Umum.

Santoso,Singgih. 2010. StatistikNonparametrik. Jakarta:PT Elex Media Komputindo.

$\begin{array}{lll}\text { Singodimedjo dan } & \text { EdySutrisno. }\end{array}$ ManajemenSumberDayaManusia.Jakarta:KencanaPrenadaMediaGroup.

Sutrisno, E. 2017. ManajemenSumber Daya Manusia.Kencana. Jakarta.

Sarwono. 2011.PsikologiRemaja.Jakarta: PT. Raja Grafindo.

Torang, Syamsir.2016.OrganisasidanManajemen.Bandung:CV Alfabeta.

Terry, Sutrisno. 2017.ManajemenSumberDayaManusia.Jakarta:KencanaPrenada MediaGroup. 